\title{
Heptagonal Photonic Crystal Fiber for Dispersion Compensation with a Very Low Confinement Loss
}

\author{
Md Borhan Mia, Mohammad Faisal, Syeda Iffat Naz, Kanan Roy Chowdhury, and \\ Animesh Bala Ani
}

\begin{abstract}
This paper presents a photonic crystal fiber (PCF) with heptagonal core and heptagonal cladding for dispersion compensation. Different optical properties of the suggested PCF are explored using the finite element method. The proposed dispersion compensating PCF (DC-PCF) exhibits a very large negative chromatic dispersion of $\mathbf{- 9 4 0}$ $\mathrm{ps} /(\mathrm{nm}-\mathrm{km})$ at $1550 \mathrm{~nm}$ wavelength. The dispersion variation of the $D C-P C F$ is -420.1 to $-1160 \mathrm{ps} /(\mathrm{nm}-\mathrm{km})$ in the wavelength range of 1390 to $1700 \mathrm{~nm}(310 \mathrm{~nm}$ band). The relative dispersion slope is $0.0036 \mathrm{~nm}^{-1}$ which is a perfect match with the standard single mode fibers. Moreover, it exhibits a very low confinement loss of about $10^{-5} \mathrm{~dB} / \mathrm{km}$ and low nonlinearity of $45 \mathrm{~W}^{-1} \mathrm{~km}^{-1}$ at $1550 \mathrm{~nm}$ wavelength. Since the suggested DC-PCF has very high negative dispersion and low nonlinearity, it could be a potential candidate for broadband dispersion compensation in fiber-optic communication.
\end{abstract}

Index Terms-Confinement loss; Chromatic dispersion; Finite element method; Photonic crystal fiber

\section{INTRODUCTION}

W avelength division multiplexed (WDM) and dense wavelength division multiplexed (DWDM) based fiberoptic transmission networks are widely used to transport high bit rate and ultra-high bit rate data [1]. Due to growing demand of various services, e.g., wireless digital cameras, video conferencing, online video streaming,

Manuscript received October 9, 2001. (Write the date on which you submitted your paper for review.) Paper titles should be written in uppercase and lowercase letters, not all uppercase. Write "[Invited]" in the title if your paper was invited to appear in a feature or focus issue. Full names of authors are preferred, not required, in the author field. Put a space between authors' initials.

F. A. Author is with the National Institute of Standards and Technology, Boulder, Colorado 80305, USA (corresponding author to provide e-mail: author@ boulder.nist.gov).

S. B. Author, Jr., was with Rice University, Houston, Texas 77005, USA. He is now with the Department of Physics, Colorado State University, Fort Collins, Colorado 80523, USA.

T. C. Author is with the Electrical Engineering Department, University of Colorado, Boulder, Colorado 80309, USA, on leave from the National Research Institute for Metals, Tsukuba, Japan. gaming on demand, IPTV, telemetry, cloud computing, Internet of things (IoT) etc., the data over the telecommunication links are increasing day by day. In WDM systems, the bit rate of $40 \mathrm{~Gb} / \mathrm{s}$ has been widely used [2]. Moreover, data rate per channel of $100 \mathrm{~Gb} / \mathrm{s}$ [3] and 400 $\mathrm{Gb} / \mathrm{s}$ [4] have been realized in order to transport massive data over WDM and DWDM systems for long-haul transmission. The optical fiber has mainly two linear impairments, namely, attenuation and dispersion which require to be mitigated. Between the two, the chromatic dispersion is more detrimental and it imposes a considerable limitation as it broadens the optical pulses propagating through the fiber. With the increase of demand for capacity, the bit rate increases and the pulse width decreases which consequently further enhances the pulse broadening and drastically reduces the performance of the systems. Therefore, dispersion compensation is indispensable in fiber-optic communication.

Standard single mode fibers (SMFs) are mostly deployed in fiber-optic transmission links which have a typical dispersion of 15 to $20 \mathrm{ps} /(\mathrm{nm}-\mathrm{km})$ at $1550 \mathrm{~nm}$ wavelength. This will cause a huge accumulated dispersion along the transmission line. To compensate this dispersion of the SMFs, different strategies have been adopted such as conventional dispersion compensating fibers (DCFs) [5], electronic dispersion compensation [6], Bragg grating fibers [7] and optical phase conjugation [8] etc. Among these techniques, DCFs are widely used due to their negative dispersion, low loss and low nonlinearity [9]. Furthermore, compensation is done in optical domain with ease of coupling with SMF, if we use DCFs. Dispersion compensating PCF (DC-PCF) offers additional benefit by tailoring the optical properties like dispersion, loss and birefringence etc. We use DC-PCF to achieve desirable negative dispersion with suitable slope, low or high birefringence, and further reduction in the losses. Therefore, DC-PCFs are preferred over DCFs.

In recent years, photonic crystal fibers (PCFs) or micro-structure optical fibers (MOFs) consisting of air hole channel running down their length have earned a lot of interest due to their sui-generis properties and potential applications. Their optical properties are easily engineered since they have various tuneable design parameters such as pitch, diameter, shape and number of air holes and air-hole rings around the core as well as the cladding region [5][10]. These flexibilities of the PCFs make it suitable and potential to supersede SMFs and DCFs. There are some 
other attractive properties that can be tailored from the PCFs such as improved birefringence, nonlinearity, large effective area, splice loss, bending loss etc. Physical shapes of the PCFs are quite feasible today because of the invention of fabrication techniques like stack and draw [11], drilling and extrusion [12], sol-gel casting [13] etc.

The idea to use PCF in dispersion compensation was first introduced by Birks et al. [14] who proposed a PCF showing chromatic dispersion of $-2 \times 10^{-3} \mathrm{ps} /(\mathrm{nm}-\mathrm{km})$ at $1550 \mathrm{~nm}$ wavelength. Kim et al. [15] has proposed a PCF displaying dispersion of $-156 \pm 0.5 \mathrm{ps} /(\mathrm{nm}-\mathrm{km})$ over the wavelength range of $\mathrm{C}+\mathrm{L}$ bands. However, the core and cladding consist of elliptical air holes which are difficult to fabricate, difficult to coupling and dispersion value is very low. Habib et al. [16] proposed a PCF of dispersion -588 $\mathrm{ps} /(\mathrm{nm}-\mathrm{km})$ at $1550 \mathrm{~nm}$. However, the confinement loss is $10^{-1} \mathrm{~dB} / \mathrm{m}$ which is very high. In [17], Haque et al. proposed another design with chromatic dispersion of -790.12 $\mathrm{ps} /(\mathrm{nm}-\mathrm{km})$ and the confinement loss of $10^{-4} \mathrm{~dB} / \mathrm{km}$ at 1550 $\mathrm{nm}$ wavelength. However, dispersion coefficient varies from -248 to $-1069 \mathrm{ps} /(\mathrm{nm}-\mathrm{km})$ over $\mathrm{E}$ to $\mathrm{L}$ bands. In another design, Habib et al. [18] proposed an MOF for which dispersion coefficient is -130 to $-360 \mathrm{ps} /(\mathrm{nm}-\mathrm{km})$ in the wavelength range of $1400 \mathrm{~nm}$ to $1500 \mathrm{~nm}$ (100 nm band). Moreover, the background material used here is not silica but organic materials like propanol, butanol and ethanol. In [19], Hasan et al. proposed a PCF of dispersion -555.93 $\mathrm{ps} /(\mathrm{nm}-\mathrm{km})$ at the wavelength of $1550 \mathrm{~nm}$. Besides, dispersion co-efficient varies from -388.72 to $-723.1 \mathrm{ps} /(\mathrm{nm}$ $\mathrm{km}$ ) ranging from 1460 to $1625 \mathrm{~nm}$ wavelength. Additionally, confinement loss is also high, of the order of $10^{-2} \mathrm{~dB} / \mathrm{km}$ at $1550 \mathrm{~nm}$ wavelength. In [20], a structure using 5 rings of air holes is proposed whose dispersion varies from -386.57 to $-971.44 \mathrm{ps} /(\mathrm{nm}-\mathrm{km})$ over the wavelength ranging from $1400 \mathrm{~nm}$ to $1610 \mathrm{~nm}$. The chromatic dispersion at $1550 \mathrm{~nm}$ is $-790.12 \mathrm{ps} /(\mathrm{nm}-\mathrm{km})$. However, the design is much complex because of air-holes with different diameters which are angularly rotated and different pitches. All these make the design a fabrication challenge. In [21], the obtained average dispersion is -138 $\mathrm{ps} /(\mathrm{nm}-\mathrm{km})$ from $980 \mathrm{~nm}$ to $1580 \mathrm{~nm}$, however, again the design is complex since the core region consists of pentagonal shaped air holes. Besides, the confinement loss is also high. In [22], Habib et al. suggested a single-mode fiber of dispersion $-712 \mathrm{ps} /(\mathrm{nm}-\mathrm{km})$. Additionally, dispersion varies from -300 to $-1000 \mathrm{ps} /(\mathrm{nm}-\mathrm{km})$ in the wavelength range of $1340 \mathrm{~nm}$ to $1640 \mathrm{~nm}$. Monfared et al. [23] investigated a PCF and obtained dispersion of -2108 $\mathrm{ps} /(\mathrm{nm}-\mathrm{km})$ at $1550 \mathrm{~nm}$ wavelength. However, necessary information regarding relative dispersion slope (RDS) is missing. Furthermore, core is elliptical shape doped with $\mathrm{GeO}_{2}$ which makes it costlier and suffered fabrication difficulty. In [24], the chromatic dispersion at $1550 \mathrm{~nm}$ wavelength is $-672 \mathrm{ps} /(\mathrm{nm}-\mathrm{km})$. However, there are two elliptical air holes in the core and the confinement loss is very high. Additionally, dispersion varies from -470 to -850 $\mathrm{ps} /(\mathrm{nm}-\mathrm{km})$ over $\mathrm{S}$ to L bands. The PCF in [25] exhibits chromatic dispersion of $-1054.4 \mathrm{ps} /(\mathrm{nm}-\mathrm{km})$ at $1550 \mathrm{~nm}$ wavelength and RDS value match with SMFs. Notwithstanding, the structure is hybrid which increases the complexity and there is no information of confinement loss. Besides, the dispersion varies from -270 to -1100 $\mathrm{ps} /(\mathrm{nm}-\mathrm{km})$ in the wavelength range of 1340 to $1640 \mathrm{~nm}$ (300 $\mathrm{nm}$ bands). The large negative dispersion is shown in
[26], [27], however, information regarding either RDS or confinement loss is missing and the core is doped in [26] and dispersion is fluctuating in [27].

In this paper, we propose a PCF with heptagonal core and cladding for dispersion compensation. The proposed DCPCF shows a negative dispersion of $-940 \mathrm{ps} /(\mathrm{nm}-\mathrm{km})$ at the wavelength of $1550 \mathrm{~nm}$ which is higher than that of recently reported literatures [16-20]. The dispersion variation is of -420.1 to $-1160 \mathrm{ps} /(\mathrm{nm}-\mathrm{km})$ in the wavelength range of 1390 to $1700 \mathrm{~nm}$ (310 nm bands). The RDS value of the proposed DC-PCF is $0.0036 \mathrm{~nm}^{-1}$, which is perfectly matched with the SMFs. Besides, the confinement loss is very low in the order of $10^{-5} \mathrm{~dB} / \mathrm{km}$. The proposed DC-PCF operates on single mode since $V_{\text {eff }}$ parameter is less than $\Pi$ from wavelength of $1390 \mathrm{~nm}$ to $1700 \mathrm{~nm}(310 \mathrm{~nm}$ bands).

\section{GEOMETRY OF THE DESIGN}

The cross sectional view of the proposed DC-PCF is demonstrated in Fig. 1. Design is simple since the core and cladding consist of circular air holes in a shape of heptagon. For the background material silica is used, which is industrially available. The proposed design consists of total nine air hole rings divided into two sectors, i.e. inner core region and outer cladding. Inner and outer cladding both have the heptagonal shape. The core region is comprised of three air-hole rings with the pitch value of $\Lambda_{1}=0.781 \mu \mathrm{m}$ and the diameter of each hole is $\mathrm{d}_{1}=0.631 \mu \mathrm{m}$ for the optimum case. It is evident that change of diameter of air hole or pitch near the core region strongly affects the dispersion property of the fiber. We check the effect of both in core as well as cladding for our work. The angle between two adjacent holes in core is $51.43^{\circ}$. For the outer cladding, there are 6 air-hole rings with the pitch value of $\Lambda_{2}=0.867$ $\mu \mathrm{m}$ and the hole diameter of $\mathrm{d}_{2}=0.80 \mu \mathrm{m}$ for the optimum results. As seen from the Fig. 1, the core has identical airhole with diameter of $\mathrm{d}_{1}$ and the cladding with diameter of $\mathrm{d}_{2}$. The air filling fraction in core and the cladding are chosen to be $\mathrm{d}_{1} / \Lambda_{1}=0.81$ and $\mathrm{d}_{2} / \Lambda_{2}=0.92$, respectively to achieve optimum result.

\section{MODEL AND SIMULATION METHOD}

To investigate the optical properties of the designed fiber, finite element method (FEM) is used. COMSOL MULTIPHYSICS software, version 5.0 is used as the design simulator. A circular perfectly matched layer (PML) is positioned outside the outermost ring to model the leakage and it produces no reflection.

Maxwell's equations are solved in layers comprising a finite number of homogeneous isotropic regions ended by PML. By solving the eigenvalue problem of the Maxwell's curl equation, the effective refractive index can be obtained. Maxwell's equation [28] is expressed as

$$
\vec{\Delta} \times\left\{\frac{1}{[s]} \cdot(\vec{\Delta} \times \vec{E})-k_{0}^{2} \eta^{2}[s] \vec{E}\right\}=0
$$




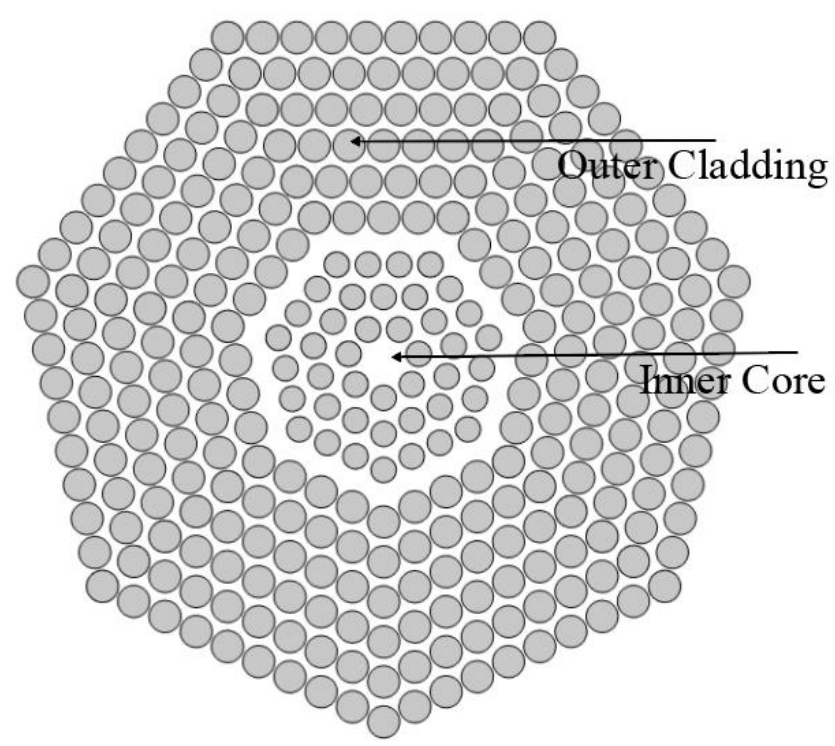

where $E$ is the electric field vector, $k_{0}=\frac{2 \pi}{a}$ is the free space

wave number, $\eta$ is the refractive index, $[\mathrm{s}]$ is the matrix of the PML circular layers and $[\mathrm{s}]^{-1}$ is the inverse matrix. Once the modal refractive index $\eta_{\text {eff }}$ is obtained, other parameters like chromatic dispersion $D(\lambda)$, nonlinear coefficient $\gamma$, confinement loss $L_{c}$, effective area $A_{\text {eff, }}$ birefringence $B$, and $V$ parameter etc. can be obtained from their respective equation [29]-[32].

$$
\begin{aligned}
& D(\lambda)=-\frac{\lambda}{c} \frac{d^{2} \operatorname{Re}\left[\eta_{e f f}\right]}{d \lambda^{2}} \\
& B=\left|\eta_{e f f}^{x}-\eta_{e f f}^{y}\right|
\end{aligned}
$$

(a)

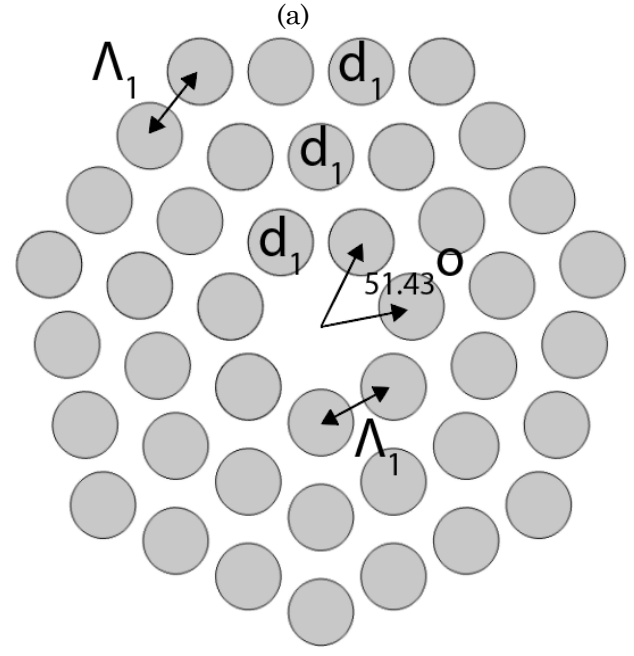

$A_{\text {eff }}=\frac{\left(\iint|E|^{2} d x d y\right)^{2}}{\iint|E|^{4} d x d y}$
$L_{c}=\frac{20 \times 10^{6}}{\ln (10)} k_{0} \operatorname{Im}\left[\eta_{\text {eff }}\right]$

where, $\operatorname{Re}\left\lfloor\eta_{\text {eff }}\right\rfloor$ and $\operatorname{Im}\left\lfloor\eta_{\text {eff }}\right\rfloor$ are the real and the imaginary part of the effective refractive indices, respectively; $\eta_{\text {eff }}^{x}$ and $\eta_{\text {eff }}^{y}$ are the refractive indices of the x and y polarization mode, respectively, $E$ is the electric field vector, $k_{0}$ is the free space wave number, $\lambda$ is the operating wavelength and $c$ is the velocity of the light in vacuum. The material dispersion is considered by applying Sellmeier formula in simulation

The change of dispersion with a small change in wavelength is known as dispersion slope and it is necessary to calculate the slope mismatch with other fibers. Dispersion slope is calculated by the following equation [33].

$S(\lambda)=\frac{d D(\lambda)}{d \lambda}$

The ratio of dispersion slope to dispersion is defined as relative dispersion slope (RDS). The RDS value of the proposed fiber is calculated by using the following equation [34].

(c)

Fig. 1. Transverse cross section of the suggested DC-PCF with the optimum parameters $d_{1}, d_{2}, \Lambda_{1}$ and $\Lambda_{2}$. (a) Full cross sectional view of DC-PCF, Cross sectional view of (b) magnified core (c) Cladding

$R D S=\frac{S_{S M F}(\lambda)}{D_{S M F}(\lambda)}=\frac{S_{D C-P C F}(\lambda)}{D_{D C-P C F}(\lambda)}$

where, $S_{S M F}(\lambda)$ and $D_{S M F}(\lambda)$ are the dispersion slope and dispersion for the SMF, respectively. Similarly, $S_{D C-P C F}(\lambda)$ and $D_{D C-P C F}(\lambda)$ are for the dispersion compensating fibers. Once we obtain the RDS of the DC-PCFs close to that of the 
standard single mode fibers (SMFs), our target will be accomplished for the broadband dispersion compensation in fiber-optic communication.

The mode property of the proposed DC-PCF is scrutinized carefully. There is a cut off frequency for each mode below which the mode cannot propagate. The normalized frequency or V-parameter of the optical fiber is a very important quantity which is used to determine the propagating modes. If $\mathrm{V}$-parameter of the fiber is less than $\pi$, fiber will allow only one mode and effectively acts as a single-mode fiber. The V-parameter, $V_{\text {eff }}$ is expressed by the following equation [35].

$$
V_{e f f}=\frac{2 \pi \Lambda}{\lambda} \sqrt{\eta_{e f f}^{2}-\eta_{F S M}^{2}}
$$

where, $\eta_{\text {eff }}$ and $\eta_{\text {FSM }}$ are the refractive indices of the fundamental mode and fundamental space filling mode, respectively.

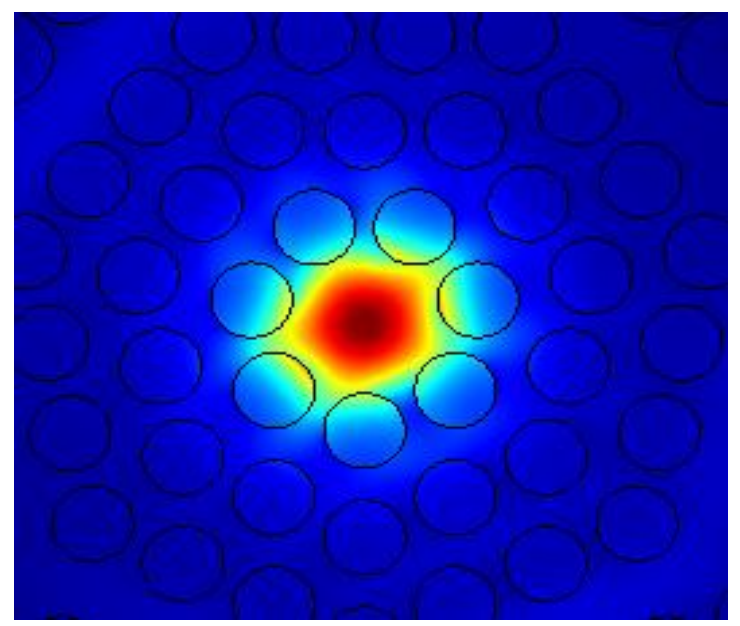

(a)

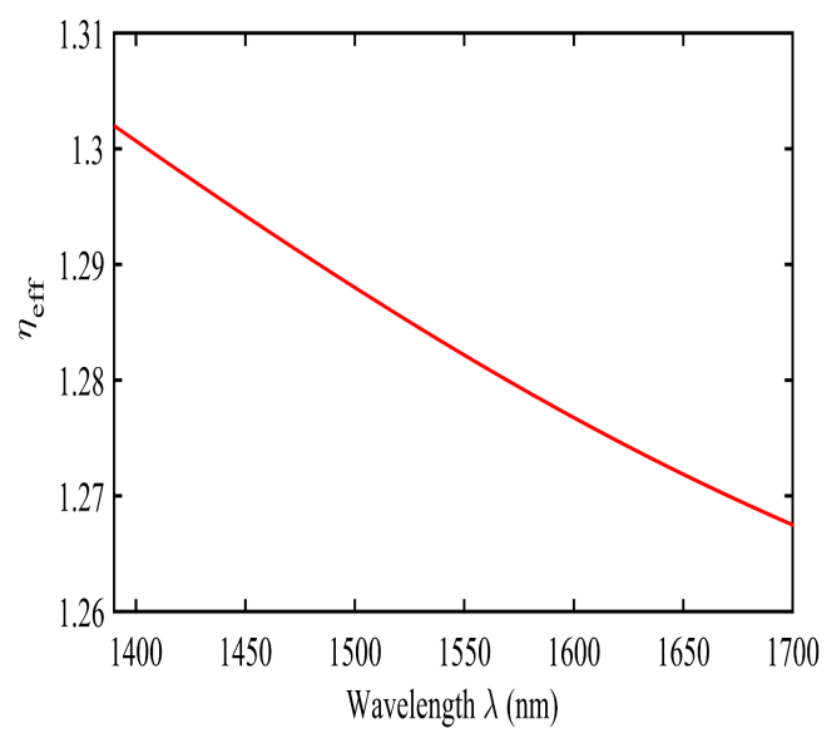

(b)

Fig. 2. With the parameter $\mathrm{d}_{1}=0.631 \mu \mathrm{m}, \Lambda_{1}=0.781 \mu \mathrm{m}, \mathrm{d}_{2}=0.80$ $\mu \mathrm{m}$ and $\Lambda_{2}=0.867 \mu \mathrm{m}$ for the proposed DC-PCF, (a) Poynting vector profile and (b) Refractive index vs. wavelength

\section{RESULTS AND DISCUSSION}

Fundamental mode field distribution and the effective refractive index of the proposed DC-PCF are presented in Fig. 2 (a) and (b), respectively. Light is well confined in the core region since higher refractive index is achieved in the core region than the cladding which results in high negative value of dispersion.

It is seen form the Fig. 2 (b) that the effective refractive index is 1.28 at $1550 \mathrm{~nm}$ wavelength. With the increase of wavelength, refractive index decreases indicating that power is well confined in core region at lower wavelength.

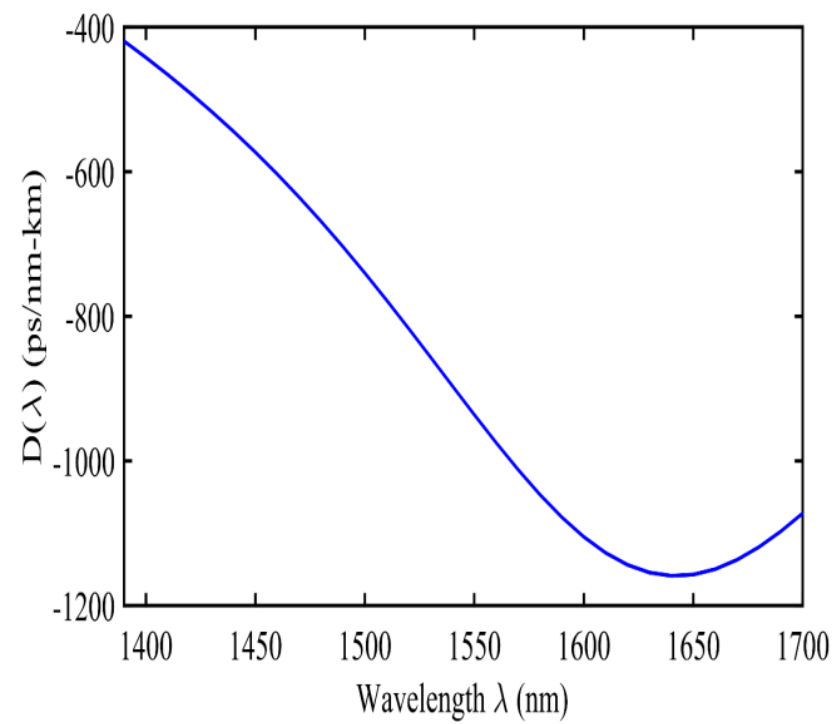

(a)

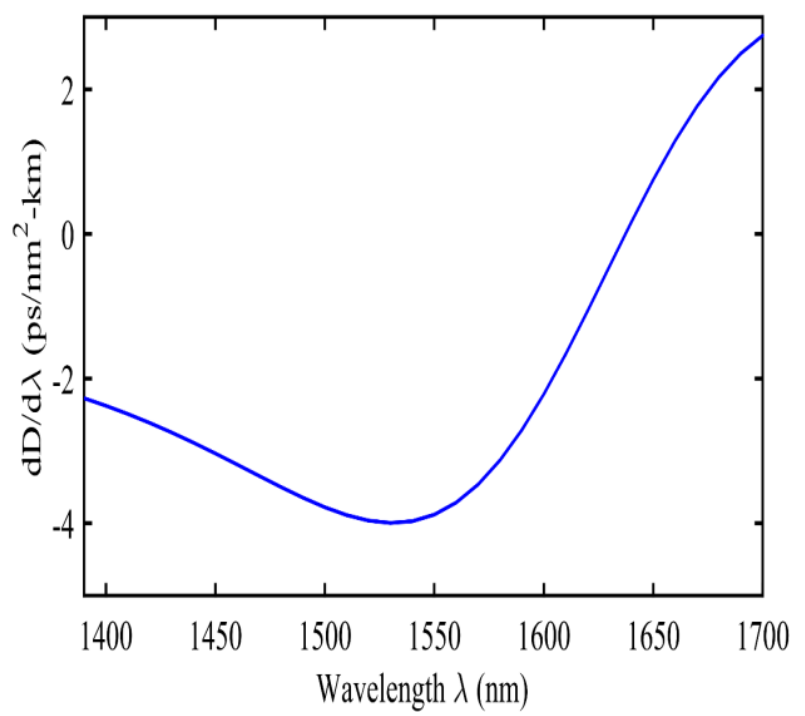

(b)

Fig. 3. Optimum parameter $\mathrm{d}_{1}=0.631 \mu \mathrm{m}, \Lambda_{1}=0.781 \mu \mathrm{m}, \mathrm{d}_{2}$ $=0.80 \mu \mathrm{m}$ and $\Lambda_{2}=0.867$ (a) Chromatic dispersion (b) dispersion slope as a function of wavelength.

Firstly, we have changed core diameter $\mathrm{d}_{1}$ keeping other parameters constant, i.e., $\Lambda_{1}=0.781 \mu \mathrm{m}, \Lambda_{2}=0.867 \mu \mathrm{m}$ and $\mathrm{d}_{2}=0.80 \mu \mathrm{m}$. Taking the value of $\mathrm{d}_{1}$ as $0.621,0.631,0.641$ $\mu \mathrm{m}$, the corresponding chromatic dispersions are found $-890,-940,-1000 \mathrm{ps} /(\mathrm{nm}-\mathrm{km})$, respectively. Calculated 
RDS values are $0.00416,0.0036$ and $0.0049 \mathrm{~nm}^{-1}$ at $\mathrm{d}_{1}=$ $0.621,0.631$ and $0.641 \mu \mathrm{m}$, respectively at $1550 \mathrm{~nm}$ wavelength. The effect of variation of diameter $d_{1}$ on chromatic dispersion is depicted in Fig. 4. Moreover, the confinement loss of the proposed PCF to the corresponding diameters, $\mathrm{d}_{1}=0.621,0.631,0.641 \mu \mathrm{m}$ are $4.64 \times 10^{-6}, 1 \times 10^{-5}$ and $1.46 \times 10^{-5} \mathrm{~dB} / \mathrm{km}$, respectively and it is seen in Fig. 5 .

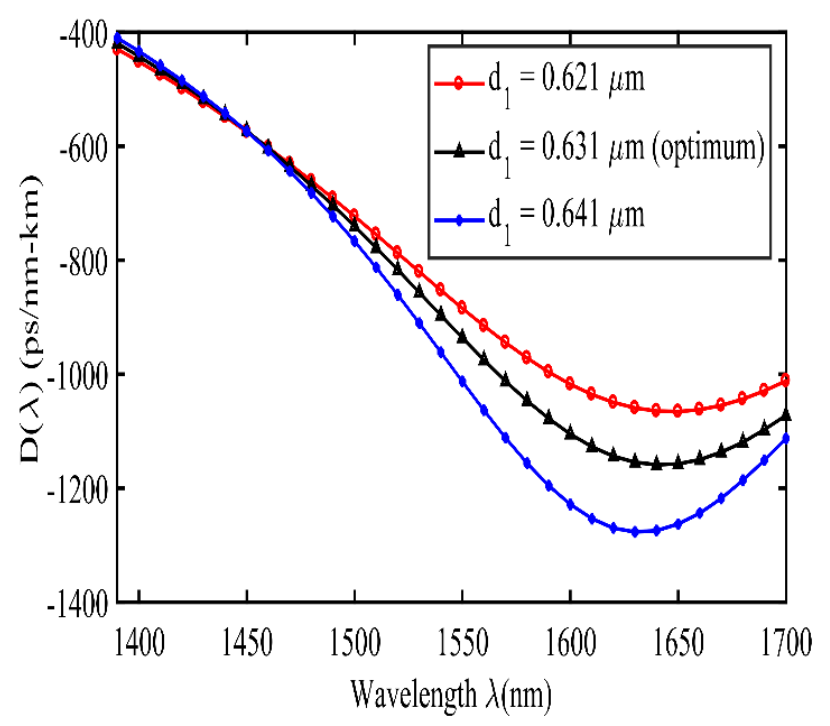

Fig. 4. Chromatic dispersion of the signified DC-PCF as function of wavelength with the parameter $\mathrm{d}_{1}$ taken as $0.621 \mu \mathrm{m}, 0.631 \mu \mathrm{m}$ and $0.641 \mu \mathrm{m}$ keeping $\mathrm{d}_{2}, \Lambda_{2}$ and $\Lambda_{1}$ unaltered.

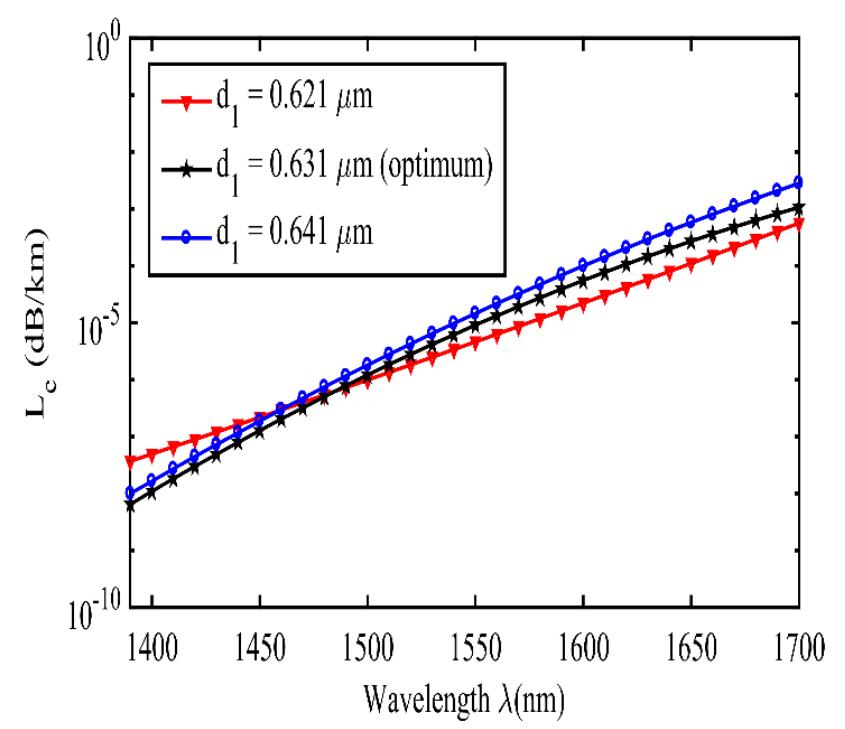

Fig. 5. Confinement loss vs. wavelength with parameter $\mathrm{d}_{1}$ taken as $0.621 \mu \mathrm{m}, 0.631 \mu \mathrm{m}$ and $0.641 \mu \mathrm{m}$ keeping $\mathrm{d}_{2}, \Lambda_{2}$ and $\Lambda_{1}$ unchanged.

Later on, we keep $\mathrm{d}_{1}=0.631 \mu \mathrm{m}, \mathrm{d}_{2}=0.80 \mu \mathrm{m}$ and $\Lambda_{2}=$ $0.867 \mu \mathrm{m}$ unchanged and vary the value of $\Lambda_{1}$ in core. The chromatic dispersion of the proposed PCF with the changing values of $\Lambda_{1}$ is shown in the Fig. $6 . \Lambda_{1}$ is chosen as 0.779 , 0.781 and $0.782 \mu \mathrm{m}$ while the calculated dispersion is -840 , -940 and $-1010 \mathrm{ps} /(\mathrm{nm}-\mathrm{km})$, respectively. The calculated RDS values are $0.0040,0.0036,0.0043 \mathrm{~nm}^{-1}$, respectively at $1550 \mathrm{~nm}$ wavelength. The confinement loss for varying core pitch, $\Lambda_{1}$ is demonstrated in the Fig. 7. It is seen from the Fig. 7 the confinement loss is $6.14 \times 10^{-6}, 1 \times 10^{-5}$ and $1.28 \times 10^{-5} \mathrm{~dB} / \mathrm{km}$ for the pitch of $\Lambda_{1}=0.779,0.781$ and 0.782 $\mu \mathrm{m}$, respectively.

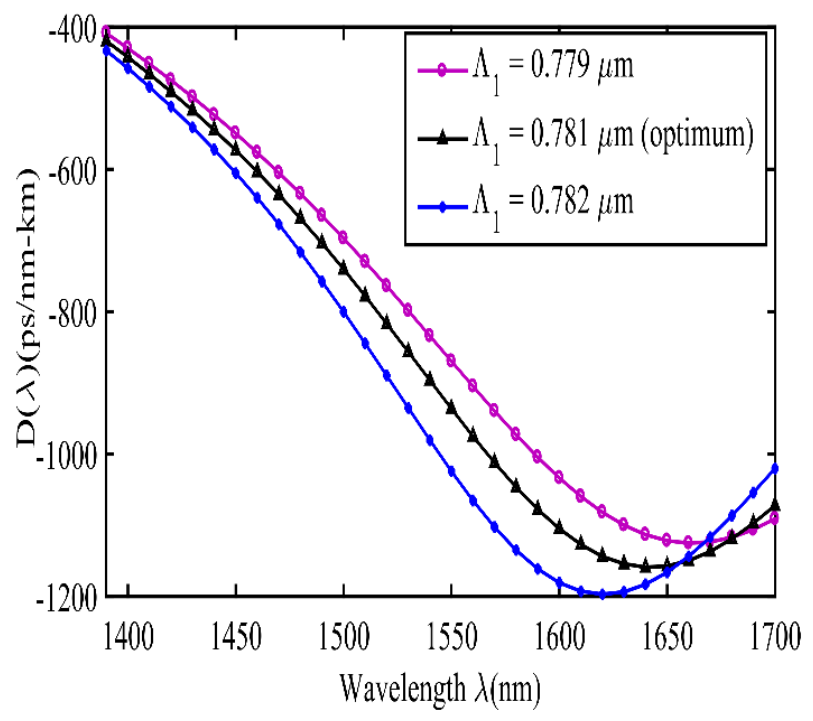

Fig. 6. Chromatic dispersion of the denoted DC-PCF as function of wavelength with the parameter $\Lambda_{1}$ taken as $0.779 \mu \mathrm{m}, 0.781 \mu \mathrm{m}$ and $0.782 \mu \mathrm{m}$ keeping $\mathrm{d}_{2}, \Lambda_{2}$ and $\mathrm{d}_{1}$ unchanged.

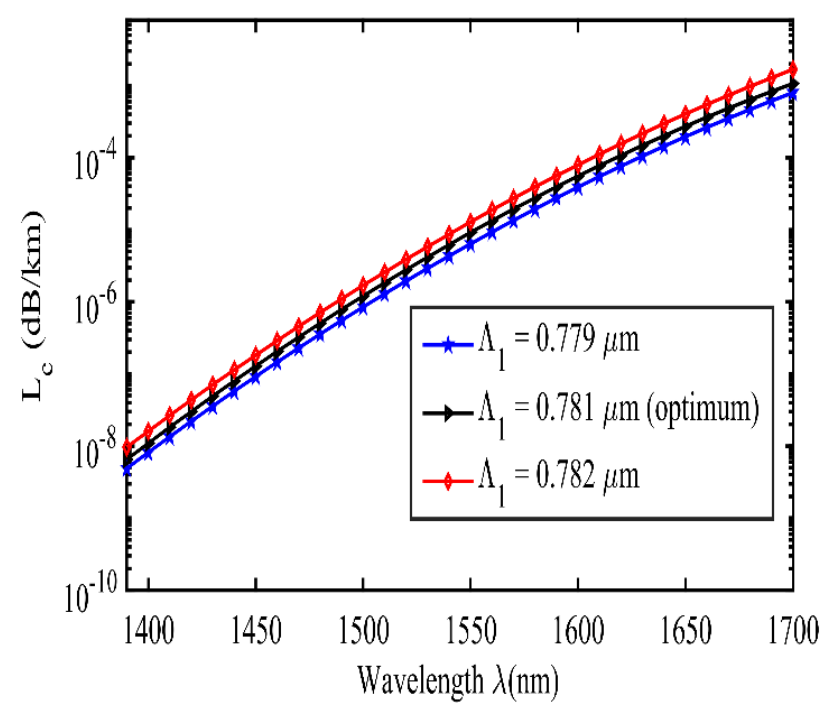

Fig. 7. Confinement Loss of the proposed DC-PCF as function of wavelength with the parameter $\Lambda_{1}$ taken as $0.779 \mu \mathrm{m}, 0.781 \mu \mathrm{m}$ and $0.782 \mu \mathrm{m}$ keeping $\mathrm{d}_{2}, \Lambda_{2}$ and $\mathrm{d}_{1}$ untouched.

The above discussion reveals that whether $\mathrm{d}_{1}$ value is increased or decreased, either way, RDS value moves away from $0.0036 \mathrm{~nm}^{-1}$ though the chromatic dispersion increases with the increment of $d_{1}$ at the wavelength of $1550 \mathrm{~nm}$. On the other hand, the increment or decrement of $\Lambda_{1}$ has the same effect as $d_{1}$. So the optimum core diameter and pitch are chosen to be $d_{1}=0.631 \mu \mathrm{m}$ and $\Lambda_{1}=0.781 \mu \mathrm{m}$, respectively. The confinement loss from the Fig. 5 reveals that with the increment of $d_{1}$ loss will increase since optical field moves towards the cladding region for large $d_{1}$. From 
the Fig. 7, the confinement loss increases for the large pitch $\Lambda_{1}$, due to mode field travels to cladding region.

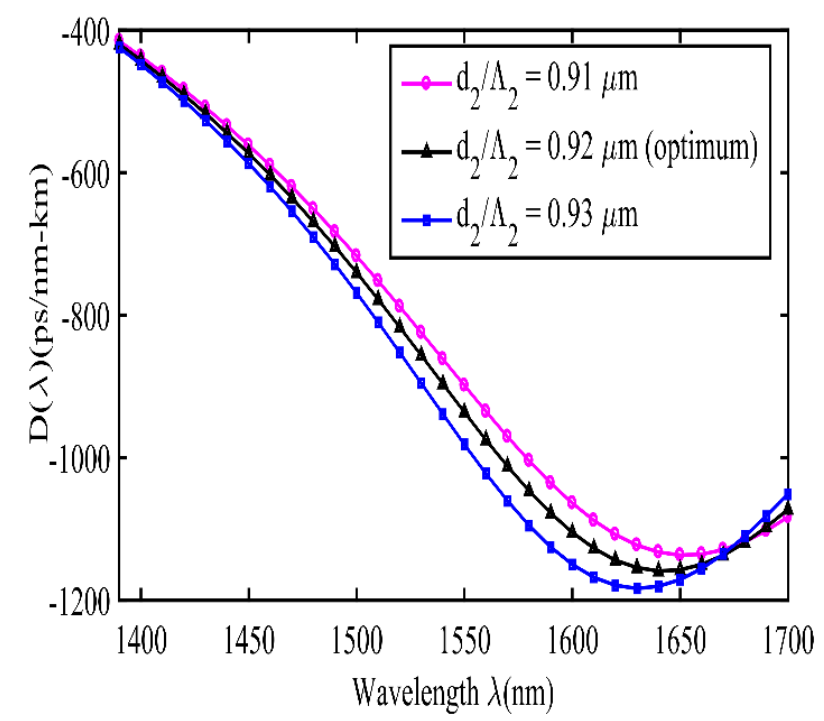

Fig. 8. The proposed DC-PCF's chromatic dispersion as a function of wavelength changing $\mathrm{d}_{2} / \Lambda_{2}$ from $0.91 \mu \mathrm{m}$ to $0.93 \mu \mathrm{m}$ keeping other parameters unaltered.

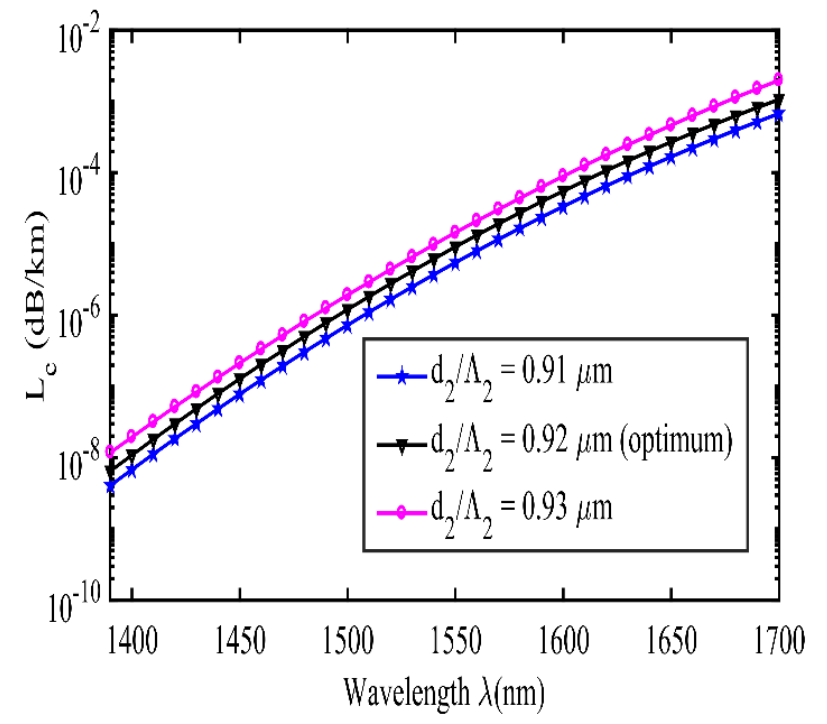

Fig. 9. Confinement loss vs. wavelength for the changing $d_{2} / \Lambda_{2}$ from $0.91 \mu \mathrm{m}$ to $0.93 \mu \mathrm{m}$ keeping other parameters unaltered.

To explore the effect of the outer cladding, we have changed the $\mathrm{d}_{2} / \Lambda_{2}$ ratio keeping $\mathrm{d}_{1}=0.631 \mu \mathrm{m}$ and $\Lambda_{1}=0.781$ $\mu \mathrm{m}$ unaltered. The value of $\mathrm{d}_{2} / \Lambda_{2}$ is taken as $0.91,0.92$ and $0.93 \mu \mathrm{m}$ and the corresponding dispersion curves are shown in the Fig. 8. Since the parameter $\mathrm{d}_{2} / \Lambda_{2}$ is changing from $0.91 \mu \mathrm{m}$ to $0.93 \mu \mathrm{m}$, the chromatic dispersion has increased. The chromatic dispersions are $-900,-940$ and -980 for $\mathrm{d}_{2} / \Lambda_{2}=0.91,0.92$ and 0.93 , respectively at communication band. However, RDS values at $1550 \mathrm{~nm}$ are obtained as $0.004,0.0036$, and $0.0048 \mathrm{~nm}^{-1}$, respectively. The confinement loss is demonstrated in the Fig. 9 and found
$5.50 \times 10^{-6}, 1 \times 10^{-5}$ and $1.50 \times 10^{-5} \mathrm{~dB} / \mathrm{km}$, respectively at 1550 $\mathrm{nm}$ wavelength. The confinement loss is decreased below the value of $d_{2} / \Lambda_{2}=0.92$ and increased above the below of $\mathrm{d}_{2} / \Lambda_{2}=0.92$. This is because the optical field is more confine when the ratio of $\mathrm{d}_{2} / \Lambda_{2}=0.92$. Therefore, the optimum parameters of the proposed fiber are taken to be $d_{2} / \Lambda_{2}=$ $0.92, \mathrm{~d}_{1}=0.631 \mu \mathrm{m}$ and $\Lambda_{1}=0.781 \mu \mathrm{m}$.

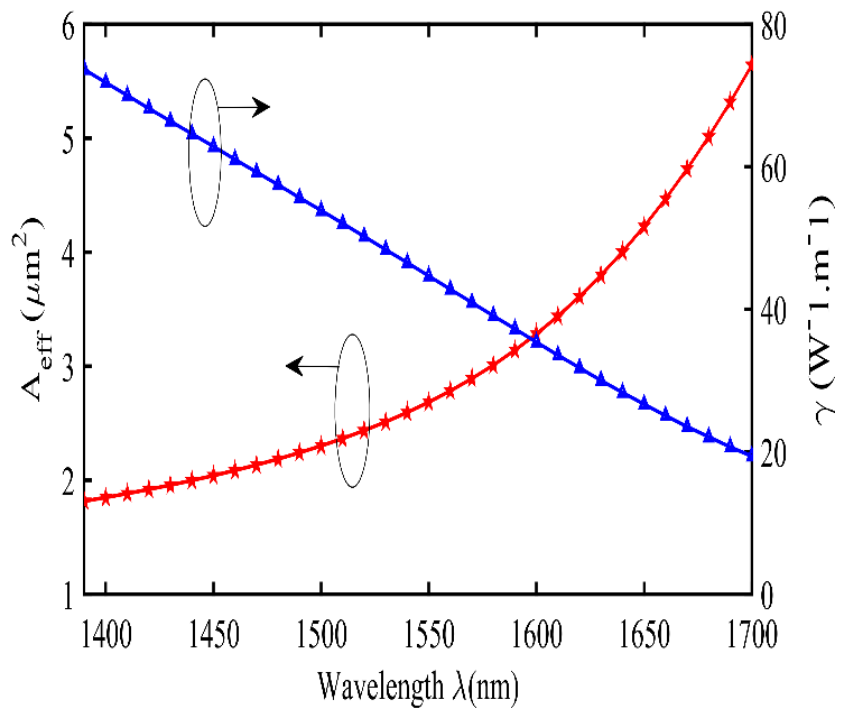

Fig. 10. Nonlinear co-efficient and effective area as a function of wavelength for the optimum parameter of the Proposed DC-PCF.

The effective area and the nonlinearity of the proposed fiber are depicted in Fig. 10 for the optimum values of parameters $\mathrm{d}_{1}, \mathrm{~d}_{2}, \Lambda_{1}$ and $\Lambda_{2}$. It is clear from the Fig. 10 that at $1550 \mathrm{~nm}$ wavelength the effective area is $2.5 \mu \mathrm{m}^{2}$ and the nonlinear co-efficient is $45 \mathrm{~W}^{-1} \mathrm{~km}^{-1}$ which is low. Therefore, the proposed fiber won't be much affected by the nonlinearity.

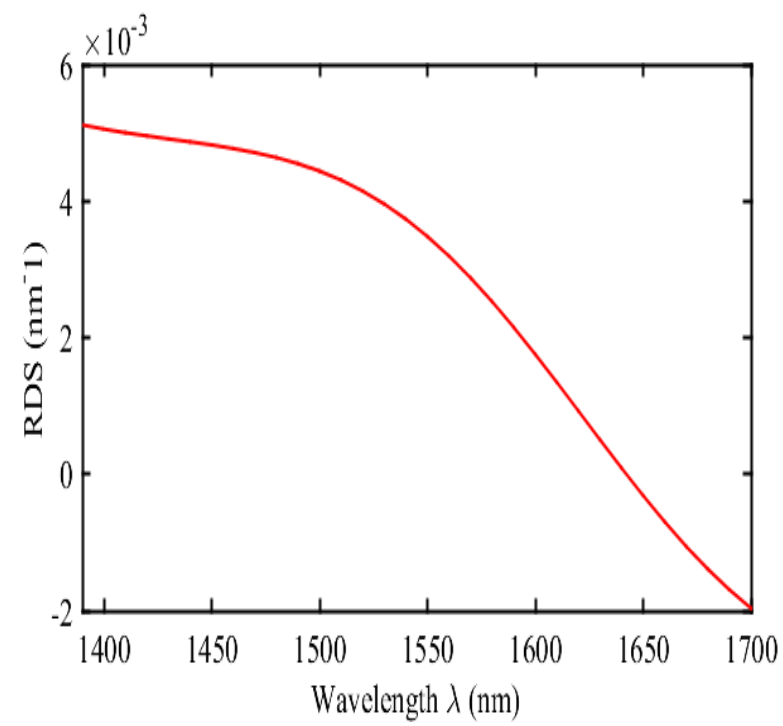

Fig. 11. RDS of the proposed DC-PCF vs. wavelength for the optimum parameters $\mathrm{d}_{1}, \Lambda_{1}, \mathrm{~d}_{2}$ and $\Lambda_{2}$. 
The RDS of the proposed DC-PCF is shown in the Fig. 11 and it is realized the RDS value of recommended DC-PCF is close to that of SMFs; nominally it is $0.0036 \mathrm{~nm}^{-1}$ at 1550 $\mathrm{nm}$ wavelength. Since RDS is used to judge the dispersion compensation (DC), the proposed fiber is a perfect candidate for broadband dispersion compensation.

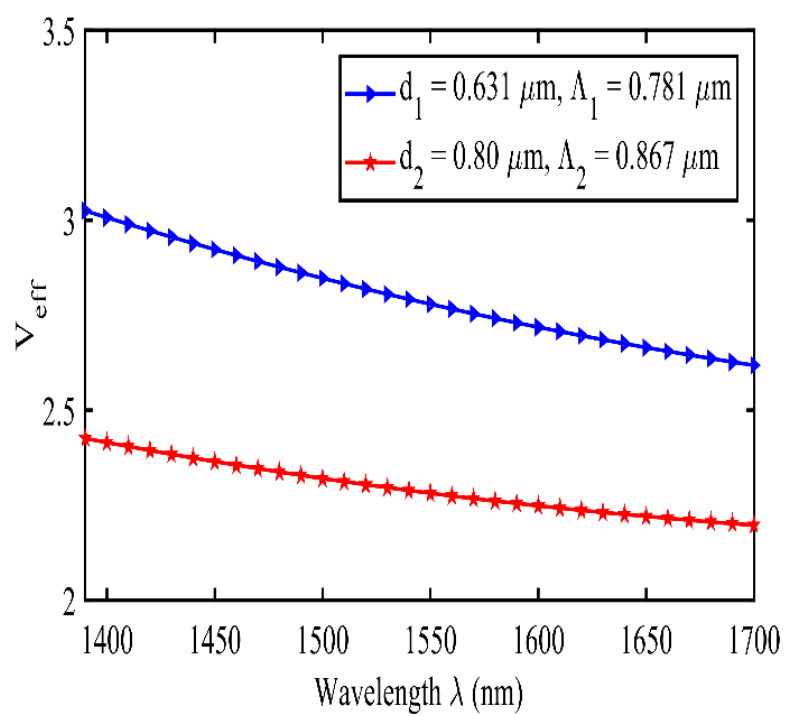

Fig. 12. V-parameter of the proposed DC-PCF as a function of wavelength for the inner and outer cladding with the optimum geometric entities.

The DC-PCF can be operated as a SMF if V-parameter, $V_{\text {eff }} \leq \Pi$. If $V_{\text {eff }}$ is greater than the $\Pi$, higher order modes get associated with it. The V-parameter of the proposed DCPCF is presented in Fig. 12. From the Fig. 12, the obtained value for $V_{\text {eff }}$ is less than $\Pi$ from $1390 \mathrm{~nm}$ to $1760 \mathrm{~nm}$ wavelength (310 $\mathrm{nm}$ bands). So, it is ensured that the proposed DC-PCF will operate as single-mode over the $\mathrm{O}+\mathrm{E}+\mathrm{S}+\mathrm{C}+\mathrm{L}$ bands.

Fabrication viability is the major issue in realization of PCFs. Heterogeneous air hole diameters at the cladding region already has been fabricated using the stack-anddraw technique [36]. Bise et al. [13] used sol-gel technology to fabricate microstructure optical fibers with missing air holes. Even PCFs with high air filling fraction have been reported fabrication viability [37], [38]. All these methods could be used to fabricate our proposed DC-PCF, however, stack-and-draw technique will be more convenient.

Finally in Table 1, we compare our work with some recently published works for compensating dispersion. It is seen from the table, our proposed DC-PCF has offered much better results with simpler design.
TABLE I

COMPARISON OF PROPOSED DC-PCF WITH RECENT ARTICLES

\begin{tabular}{|c|c|c|c|}
\hline Ref & $\begin{array}{c}\mathrm{D} \text { at } \\
1550 \mathrm{~nm} \\
(\mathrm{ps} /(\mathrm{nm}- \\
\mathrm{km}))\end{array}$ & $\begin{array}{c}\mathrm{L}_{\mathrm{c}} \text { at } \\
1550 \mathrm{~nm} \\
(\mathrm{~dB} / \mathrm{km})\end{array}$ & $\begin{array}{l}\text { Dispersion variation } \\
(\mathrm{ps} /(\mathrm{nm}-\mathrm{km}))\end{array}$ \\
\hline 16 & -588 & $10^{3}$ & $\begin{array}{c}-400 \text { to }-725 \\
(165 \mathrm{~nm} \text { bands })\end{array}$ \\
\hline 17 & -790.12 & $10^{-4}$ & $\begin{array}{c}-248.65 \text { to }-1069(270 \\
\text { nm bands })\end{array}$ \\
\hline 19 & -555.93 & $x$ & $\begin{array}{c}-388.72 \text { to }-723.1(165 \\
\text { nm bands) }\end{array}$ \\
\hline 20 & -790.12 & $10^{-2}$ & $\begin{array}{c}-386.57 \text { to }-971.44 \\
(210 \mathrm{~nm} \text { bands })\end{array}$ \\
\hline 21 & -712 & $x$ & $\begin{array}{c}-200 \text { to }-1000(300 \mathrm{~nm} \\
\text { bands) }\end{array}$ \\
\hline 22 & -672 & $10^{-1}$ & $\begin{array}{l}-470 \text { to }-850 \\
(165 \mathrm{~nm} \text { band })\end{array}$ \\
\hline $\begin{array}{l}\text { Prop } \\
\text { osed } \\
\text { DC- }\end{array}$ & -940 & $10^{-5}$ & $\begin{array}{c}-420.1 \text { to }-1160 \\
(310 \mathrm{~nm} \text { band })\end{array}$ \\
\hline
\end{tabular}

\section{Conclusion}

Heptagonal lattice structure DC-PCF is presented in this paper which exhibits a very high chromatic dispersion of $-940 \mathrm{ps} /(\mathrm{nm}-\mathrm{km})$ at $1550 \mathrm{~nm}$ wavelength. The proposed DCPCF shows dispersion variation from -420.1 to -1160 $\mathrm{ps} /(\mathrm{nm}-\mathrm{km})$ covering the wavelength from $1440 \mathrm{~nm}$ to 1700 $\mathrm{nm}$. To our best knowledge, this is highest result compared to recently published articles [16-17], [19-20], [22], [24]. The RDS of the suggested fiber is perfectly matched with standard SMF. The proposed fiber demonstrates a very low confinement loss of $10^{-5} \mathrm{~dB} / \mathrm{km}$ at the wavelength of 1550 $\mathrm{nm}$. In addition, the proposed DC-PCF operates on single mode over a wide telecom band. So, our suggested DC-PCF can be a suitable choice for broadband dispersion compensation.

\section{ACKNOWLEDGMENT}

This article is based on our own research work and we have not received any fund from any organization.

\section{REFERENCES}

[1] M. L. Loeb and G. R. Stilwell, "High-speed data transmission on an optical fiber using a byte-wide WDM system," J. Light. Technol., vol. 6, no. 8, pp. 1306-1311, 1988.

[2] K. Fukuchi et al., "10.92-Tb/s (273 x 40-Gb/s) tripleband/ultra-dense WDM optical-repeatered transmission experiment," in Optical Fiber Communication Conference, 2001, p. PD24.

[3] L. W. D. M. Transmission et al., "No-Guard-Interval Coherent Optical OFDM for," J. Light. Technol. Vol. 27, Issue 16, pp. 3705-3713, vol. 27, no. 16, pp. 3705-3713, Aug. 2009.

[4] X. Zhou et al., "High Spectral Efficiency 400 Gb/s Transmission and Training-Assisted Carrier Recovery," J. Light. Technol. Vol. 31, Issue 7, pp. 999-1005, vol. 31, no. 7, pp. 999-1005, Apr. 2013.

[5] B. Zsigri, J. Lægsgaard, and A. Bjarklev, "A novel photonic 
crystal fibre design for dispersion compensation," J. Opt. A Pure Appl. Opt., vol. 6, no. 7, pp. 717-720, Jul. 2004.

[6] N. M. Litchinitser, B. J. Eggleton, and D. B. Patterson, "Fiber Bragg gratings for dispersion compensation in transmission: Theoretical model and design criteria for nearly ideal pulse recompression," J. Light. Technol., vol. 15, no. 8, pp. 1303-1313, 1997.

[7] H. Bülow, F. Buchali, and A. Klekamp, "Electronic dispersion compensation," J. Light. Technol., vol. 26, no. 1, pp. 158-167, 2008.

[8] S. Watanabe, T. Naito, and T. Chikama, "Compensation of chromatic dispersion in a single-mode fiber by $\backslash$ noptical phase conjugation," IEEE Photonics Technol. Lett., vol. 5, no. 1, pp. 92-95, Jan. 1993.

[9] A. Bala, K. R. Chowdhury, M. B. Mia, and M. Faisal, "Highly birefringent, highly negative dispersion compensating photonic crystal fiber," Appl. Opt., vol. 56, no. 25, p. 7256, Sep. 2017.

[10] J. Broeng, D. Mogilevstev, S. E. Barkou, and A. Bjarklev, "Photonic Crystal Fibers: A New Class of Optical Waveguides," Opt. Fiber Technol., vol. 5, no. 3, pp. 305330, Jul. 1999.

[11] P. S. J. Russell, "Photonic-Crystal Fibers," J. Light. Technol. Vol. 24, Issue 12, pp. 4729-4749, vol. 24, no. 12, pp. 4729-4749, Dec. 2006.

[12] M. C. J. Large et al., "Microstructured polymer optical fibres: New opportunities and challenges," Proc. Mol. Cryst. Liq. Cryst., vol. 446, no. 1, pp. 219-31, Apr. 2006.

[13] R. T. Bise and D. J. Trevor, "Sol-gel derived microstructured fiber: fabrication and characterization," OFC/NFOEC Tech. Dig. Opt. Fiber Commun. Conf. 2005., vol. 3, pp. 11-13, 2005

[14] T. A. Birks, D. Mogilevtsev, J. C. Knight, and P. S. J. Russell, "Dispersion compensation using single-material fibers," IEEE Photonics Technol. Lett., vol. 11, no. 6, pp. 674-676, Jun. 1999.

[15] S. E. Kim, B. H. Kim, C. G. Lee, S. Lee, K. Oh, and C.-S. Kee, "Elliptical defected core photonic crystal fiber with high birefringence and negative flattened dispersion," Opt. Express, vol. 20, no. 2, p. 1385, Jan. 2012.

[16] M. Selim Habib, M. Samiul Habib, S. M. Abdur Razzak, and M. Anwar Hossain, "Proposal for highly bi-refringent broadband dispersion compensating octagonal photonic crystal fiber," Opt. Fiber Technol., vol. 19, no. 5, pp. 461467, Oct. 2013.

[17] M. M. Haque, M. S. Rahman, M. Samiul Habib, M. Selim Habib, and S. M. A. Razzak, "A new circular photonic crystal fiber for effective dispersion compensation over e to L wavelength bands," J. Microwaves, Optoelectron. Electromagn. Appl., vol. 12, no. 2, pp. 281-291, Dec. 2013.

[18] M. Selim Habib, M. Samiul Habib, S. M. Abdur Razzak, Y. Namihira, M. A. Hossain, and M. A. Goffar Khan, "Broadband dispersion compensation of conventional single mode fibers using microstructure optical fibers," Optik (Stuttg)., vol. 124, no. 19, pp. 3851-3855, Oct. 2013.

[19] M. I. Hasan, M. Selim Habib, M. Samiul Habib, and S. M. Abdur Razzak, "Highly nonlinear and highly birefringent dispersion compensating photonic crystal fiber," Opt. Fiber Technol., vol. 20, no. 1, pp. 32-38, Jan. 2014.

[20] M. M. Haque, M. S. Rahman, M. S. Habib, and S. M. A. Razzak, "Design and characterization of single mode circular photonic crystal fiber for broadband dispersion compensation," Opt. - Int. J. Light Electron Opt., vol. 125, no. 11, pp. 2608-2611, Jun. 2014.

[21] M. Samiul Habib, M. Selim Habib, M. I. Hasan, and S. M. A. Razzak, "A single mode ultra flat high negative residual dispersion compensating photonic crystal fiber," Opt. Fiber Technol., vol. 20, no. 4, pp. 328-332, Aug. 2014.

[22] M. Samiul Habib, R. Ahmad, M. Selim Habib, and S. M. A. Razzak, "Design of single polarization single mode dispersion compensating photonic crystal fiber," Opt. - Int. J. Light Electron Opt., vol. 125, no. 16, pp. 4313-4318,
Aug. 2014.

[23] Y. E. Monfared and S. A. Mojtahedinia, "Highly birefrigent photonic crystal fiber with high negative dispersion for broadband dispersion compensation," Optik (Stuttg)., vol. 125, no. 20, pp. 5969-5972, Oct. 2014.

[24] M. Selim Habib, M. Mejbaul Haque, M. Samiul Habib, M. I. Hasan, M. Shaifur Rahman, and S. M. A. Razzak, "Polarization maintaining holey fibers for residual dispersion compensation over $\mathrm{S}+\mathrm{C}+\mathrm{L}$ wavelength bands," Optik (Stuttg)., vol. 125, no. 3, pp. 911-915, Feb. 2014.

[25] M. I. Hasan, M. S. Habib, M. S. Habib, and S. M. A. Razzak, "Design of hybrid photonic crystal fiber: Polarization and dispersion properties," Photonics Nanostructures - Fundam. Appl., vol. 12, no. 2, pp. 205211, Apr. 2014

[26] J. M. Hsu, W. H. Zheng, C. L. Lee, and J. S. Horng, "Theoretical investigation of a dispersion compensating photonic crystal fiber with ultra-high dispersion coefficient and extremely low confinement loss," Photonics Nanostructures - Fundam. Appl., vol. 16, pp. 1-8, Aug. 2015.

[27] R. Hao and G. Sun, "Design of photonic crystal fiber with large negative dispersion andhigh nonlinearity," Optik (Stuttg)., vol. 126, no. 22, pp. 3353-3356, Nov. 2015.

[28] K. Saitoh and M. Koshiba, "Full-vectorial imaginarydistance beam propagation method based on a finite element scheme: application to photonic crystal fibers," IEEE J. Quantum Electron., vol. 38, no. 7, pp. 927-933, Jul. 2002.

[29] A. Agrawal, N. Kejalakshmy, J. Chen, B. M. Rahman, and K. T. Grattan, "Golden spiral photonic crystal fiber: polarization and dispersion properties," Opt. Lett., vol. 33, no. 22, p. 2716, Nov. 2008.

[30] K. Saitoh and M. Koshiba, "Leakage loss and group velocity dispersion in air-core photonic bandgap fibers," Opt. Express, vol. 11, no. 23, p. 3100, Nov. 2003.

[31] K. Saitoh, M. Koshiba, T. Hasegawa, and E. Sasaoka, "Chromatic dispersion control in photonic crystal fibers: application to ultra-flattened dispersion.," Opt. Express, vol. 11, no. 8, pp. 843-852, Apr. 2003.

[32] K. Suzuki, H. Kubota, S. Kawanishi, M. Tanaka, and M. Fujita, "Optical properties of a low-loss polarizationmaintaining photonic crystal fiber.," Opt. Express, vol. 9, no. 13 , pp. 676-680, Dec. 2001.

[33] M. Samiul Habib, R. Ahmad, M. Selim Habib, and M. Imran Hasan, "Residual dispersion compensation over the $\mathrm{S}+\mathrm{C}+\mathrm{L}+\mathrm{U}$ wavelength bands using highly birefringent octagonal photonic crystal fiber," Appl. Opt., vol. 53, no. 14, p. 3057, May 2014.

[34] L. Grüner-Nielsen et al., "Dispersion Compensating Fibers," Opt. Fiber Technol., vol. 6, no. 2, pp. 164-180, Apr. 2000.

[35] N. A. Mortensen, J. R. Folkenberg, M. D. Nielsen, and K. P. Hansen, "Modal cutoff and the V parameter in photonic crystal fibers," Opt. Lett., vol. 28, no. 20, p. 1879, Oct. 2003.

[36] Z. Liu, C. Wu, M.-L. Vincent Tse, C. Lu, and H.-Y. Tam, "Ultrahigh birefringence index-guiding photonic crystal fiber and its application for pressure and temperature discrimination," Opt. Lett., vol. 38, no. 9, pp. 1385-1387, May 2013.

[37] D. Ghosh, S. Bose, S. Roy, and S. K. Bhadra, "Design and Fabrication of Microstructured Optical Fibers with Optimized Core Suspension for Enhanced Supercontinuum Generation," J. Light. Technol., vol. 33, no. 19, pp. 41564162 , Oct. 2015.

[38] S. O. Leonov, V. A. Lazarev, M. K. Tarabrin, D. A. Dvoretskiy, A. S. Pasishnik, and A. D. Pryamikov, "Visible supercontinuum generation in large-core photonic crystal fiber with high air-filling fraction," J. Phys. Conf. Ser., vol. 584, no. 1, p. 12015, Jan. 2015. 
Md Borhan Mia was with the Electrical and Electronic Engineering Department, Bangladesh University of Engineering and Technology, Dhaka, Bangladesh.

Dr. Mohammad Faisal is with the Electrical and Electronic Engineering Department, Bangladesh University of Engineering and Technology, Dhaka, Bangladesh.

Syeda Iffat Naz was with the Electrical and Electronic Engineering Department, Bangladesh University of Engineering and Technology, Dhaka, Bangladesh.

Kanan Roy Chowdhury was with the Electrical and Electronic Engineering Department, Chittagong University of Engineering and Technology, Chittagong, Bangladesh.

Animesh Bala was with the Electrical and Electronic Engineering Department, Bangladesh University of Engineering and Technology, Dhaka, Bangladesh. 